\title{
Considerações sobre as anorexias e as especificidades das neuroses contemporâneas*1
}

\section{Considerations on anorexia and specificities of contemporary neuroses}

\author{
Flavia Lana Garcia de Oliveira*2 \\ Tania Coelho dos Santos*3
}

Partimos das anorexias como campo clínico para elucidar o que particulariza o modo neurótico contemporâneo de relação com os objetos. Demonstramos a acepção mais difundida do sintoma anoréxico na psicanálise como inscrição na literalidade do corpo da falta no viés da histeria, referida a uma resposta precária diante de um Outro que é frágil em sua função simbólica. Problematizamos essa leitura à luz das características da sociedade atual, destacando a incidência de uma posição fantasmática inclinada para a lógica do consumidor insatisfeito e para o desmentido banal da autoridade simbólica.

Palavras-chave: Anorexia, psicanálise, neuroses contemporâneas, desmentido

*1 Este artigo é baseado na tese de doutorado "Neuroses contemporâneas: o caso dos transtornos alimentares" (2017), realizada no Programa de Pós-Graduação em Teoria Psicanalítica da Universidade Federal do Rio de Janeiro - UFRJ, sob orientação da Profa. Dra. Tania Coelho dos Santos e pertence ao projeto de pesquisa "O real na ciência e o Real na prática do psicanalista", coordenado pela Profa. Dra. Tania Coelho dos Santos, que é bolsista de produtividade em Pesquisa Nivel 1C do Conselho Nacional de Desenvolvimento Científico e Tecnológico - CNPq (Brasília, DF, Brasil).

*2 Instituto Sephora de Ensino e Pesquisa de Orientação Lacaniana - ISEPOL (Rio de Janeiro, RJ, Brasil).

*3 Universidade Federal do Rio de Janeiro - UFRJ (Rio de Janeiro, RJ, Brasil). 
A dúvida diagnóstica é uma problemática cada vez mais recorrente nos dias de hoje. No meio psicanalítico, há décadas ocorrem discussões de grande envergadura que têm se direcionado para a revisão e a redefinição das ferramentas clínicas clássicas. Psicanalistas de orientação lacaniana concordam que a notória e crescente vacilação da metáfora paterna, como suporte simbólico da constituição subjetiva, questiona a abordagem tradicional centrada na oposição nítida entre neurose versus psicose. As apresentações do adoecimento psíquico expõem irrupções pulsionais que não se mascaram pelo recalque. Pelo contrário, elas dispensam o simbólico e se manifestam sem rodeios. A hipótese de Jacques-Alain Miller acerca da psicose ordinária parece ter sido tomada por alguns psicanalistas como um novo farol na prática contemporânea (Miller et al., 2004). De fato, ela propiciou uma nova chave explicativa para modalidades de satisfação mais autistas e encerradas no gozo autoerótico. Os chamados "novos sintomas" - toxicomanias, patologias do ato e da autoflagelação, transtornos alimentares etc. — passaram a ficar sob sua mira. Nessa linha norteadora, a psicose ordinária seria o rebento da foraclusão generalizada que atingiu o Outro, a antiga primazia simbólico que já não ordena mais a sociedade atual. Jacques-Alain Miller chega a defender que na pós-modernidade o grande Outro não existe, somente comitês normativos constituídos de pares.

A suposição de que a psicose ordinária absorve todos os sintomas contemporâneos não é clinicamente verificável no contexto de psicopatologias do circuito da pulsão oral como a anorexia. Algumas dessas configurações sintomáticas revelam a sujeição do funcionamento psíquico do indivíduo ao complexo de Édipo, aos Outros parentais, assim como a fixações fantasmáticas. Por outro lado, em considerável parcela de casos, observamos uma precariedade dos recursos simbólicos para subjetivação da castração, sem que forçosamente se trate de uma psicose, apesar das desregulações importantes que põem em risco a eficácia do supereu paterno, isto é, da inscrição da castração enquanto barreira que a sexualidade ergue 


\section{ARTIGOS}

à pulsão de morte, bem como a diferenciação entre o eu e o isso. Desse modo, a difícil intervenção analítica nessa casuística justifica articular a incidência de um transtorno alimentar como a anorexia ao que particulariza o modo neurótico contemporâneo de relação com os objetos.

Reiteramos, assim, a importância da escuta do inconsciente, da relação ao falo, da posição de gozo e das especificidades do laço com o Outro que são verificáveis na investigação dessas circunstâncias. Psicanalistas de orientação lacaniana como Marie-Hélène Brousse (2014) ratificaram a legitimidade de uma investigação mais dedicada à evolução das neuroses na transição de épocas. Entretanto, foi Freud quem primeiro autorizou esse desdobramento, ao observar a aparição cada vez mais recorrente de estados psíquicos que não são psicóticos, mas que chamam a atenção por seu "montante da rigidez psíquica" (Freud, 1933/1996h, p. 151). Tais casos já o desafiavam quanto às possibilidades de êxito da psicanálise, pois conteriam em seu âmago alterações expressivas no plano do caráter. A esse respeito, Freud (p. 152) comenta que: "Já sabem os senhores que o campo de aplicação da terapia analítica se situa nas neuroses de transferência - fobias, histeria, neurose obsessiva - e, além disso, anormalidades de caráter que se desenvolvem em lugar dessas doenças" (p. 152). O antagonismo entre as reivindicações pulsionais e a renúncia pulsional, em prol da promessa civilizatória de tratamento do desamparo, dificilmente se mostra solucionável. A disputa entre essas duas forças no psiquismo fica demasiadamente acirrada.

Seguindo o percurso freudiano, pretendemos contemplar as anorexias que derivam de perturbações neuróticas próprias ao laço social contemporâneo. Nossa premissa é a de que todo sintoma, seja ele moderno ou contemporâneo, advém de certo tipo de relação com o Outro, no que isso caracteriza uma escolha de gozo e uma formação de compromisso diante da impossibilidade de abdicar dela. Abrem-se, assim, as vias investigativas tanto no nível do Outro social, cuja discursividade ancora a transmissão veiculada pelos Outros primordiais de uma criança - sujeito a advir — , quanto no nível da economia de gozo organizadora da política do sujeito em sua relação com a pulsão.

\section{Anorexias neuróticas}

A anorexia, embora claramente não seja um novo sintoma na história da humanidade, vem, mesmo assim, sendo incluída na constelação sintomática associada às peculiaridades da época atual (Rudge \& Fuks, 2017). Casos 
de magreza extrema são relatados desde a Antiguidade, com ênfase em sua conotação religiosa que incentiva os fiéis a praticar o jejum radical voluntário como um ritual de expurgamento das heresias do corpo mundano, que é considerado sujo e pecaminoso. Muitas dessas práticas foram observadas entre as santas e beatas da Igreja Católica, tendo se multiplicado no século XVIII e culminado em mortes por desnutrição (Nazar, 2013). Por isso, autores como Bidaud (1998) introduzem a vertente da anorexia "ascética" ou "sagrada", vinculada exclusivamente ao empenho obstinado voltado para a purificação do corpo com o objetivo de torná-lo lócus privilegiado da morada divina. Qualquer inferência a propósito da causalidade inconsciente desses fenômenos corporais em um período histórico anterior ao advento da modernidade parece pouco cuidadosa, já que eles se referem ao período pré-moderno que é anterior à estruturação do sujeito sobre o qual a psicanálise opera, isto é, o sujeito da ciência. O sujeito do inconsciente depende da relativização das crenças religiosas e do primado da razão que constituem o sujeito da ciência (Coelho dos Santos \& Lopes, 2013). Nada nos assegura que a constituição do psiquismo a partir da divisão subjetiva tenha se instalado. Verifica-se um uso do corpo atrelado maciçamente ao modo de regulação religioso, cujas significações remetem à figura oracular do Outro representado pela divindade e seus representantes no cenário do absolutismo monárquico.

Mas essa modalidade de aparição não abarcou toda a variedade de casos. A psiquiatria clássica adentrou nesse campo a partir do século XVII. No século XIX, essa terminologia foi cunhada pelo médico inglês William Gull e passou a compor o glossário psiquiátrico, o qual designou anorexia como uma entidade psicopatológica definida pela abstenção alimentar. O termo é de etimologia grega, derivado da conjugação do prefixo an- — privação ou ausência - com o termo -orexis, que significa apetite. Em seguida, o psiquiatra francês Charles Lasègue empreendeu uma descrição psicopatológica mais apurada desse quadro, notadamente no artigo " $\mathrm{Da}$ anorexia histérica”. Em sua sagaz exposição semiológica, Lasègue (1873/1998) argumentou em favor de uma acepção da anorexia como manifestação da histeria. Ele ressaltou a ausência do desejo de cura que perpassa a posição de pacientes anoréxicos, em contraponto a um mórbido apego e à "tenacidade implacável" da relação desses sujeitos com seu sintoma. Nessa direção, Lasègue capta o que nomeia como "segurança satisfeita", isto é, uma inflexibilidade bastante endurecida e próxima à perversão mental, incidindo como um "vício patológico do caráter". A angústia e o mal-estar acometem, acima de tudo, aqueles que cercam o anoréxico e são tomados por desespero frente ao progresso 


\section{ARTIGOS}

catastrófico do emagrecimento desenfreado que traduz a fixação irreversível na experiência da fome. Em tempos da aurora da medicina científica com a emergência do método anatomo-clínico, a causalidade da anorexia foi remetida por Lasègue a uma alteração anatomobiológica na região cerebral da hipófise.

Charcot se apoiou nessa tradição e também pôs a anorexia no leque dos sintomas histéricos (Charcot, 1890 apud Bidaud, 1998). No pensamento freudiano, a sintomatologia anoréxica não chegou a ser alvo privilegiado de investigação, tendo sido pareado de maneira pontual ao lado de um vasto repertório de sintomas, como possíveis apresentações corporais da histeria ou mesmo da melancolia. Em uma de suas conferências iniciais a respeito dos mecanismos formadores do sintoma histérico, Freud (1893/1996a) afirma que:

Os sintomas cujo rastro pudemos seguir até os referidos fatores desencadeadores desse tipo abrangem nevralgias e anestesias de naturezas muito diversas, muitas das quais haviam persistido durante anos, contraturas e paralisias, ataques histéricos e convulsões epileptoides, que os observadores consideravam como epilepsia verdadeira, petit mal e perturbações da ordem dos tiques, vômitos crônicos e anorexia, levados até o extremo de rejeição de todos os alimentos, várias formas de perturbação da visão, alucinações visuais constantemente recorrentes etc. A desproporção entre os muitos anos de duração do sintoma histérico e a ocorrência isolada que o provocou é o que estamos invariavelmente habituados a encontrar nas neuroses traumáticas. (p. 40)

A vertente histérica da anorexia obedeceria ao mesmo mecanismo formador da histeria traumática, cuja causa desencadeadora seria o afeto provocado por um trauma psíquico. Posteriormente, Freud (1924/1996e) postulou que o encontro traumático por excelência ocorre com a descoberta da diferença sexual. Trata-se da realidade da castração (Wirklichkeit), da efetividade da função paterna de interdição da satisfação incestuosa e do redimensionamento do narcisismo aí implicado. O sujeito histérico sofre, via sintoma conversivo, das reminiscências que contornam por meio da fantasia esse real difícil de suportar. Como recurso defensivo, ele tenta reverter a perda de objeto por uma fixação na fase oral do circuito libidinal. No relato de Breuer e Freud sobre o caso de Anna O., observa-se que essa paciente dedicouse de forma exclusiva aos cuidados do pai, o qual adoeceu gravemente e faleceu um ano depois. Após tal sequência de eventos, a moça é assolada por intensa angústia e tristeza. Torna-se anêmica e avessa a alimentos. Também o exame do caso de Emmy Von N. é atravessado pela recusa alimentar e pelo desânimo. Na lógica do caso, ambos os fenômenos estão conectados à morte 
imprevista do marido como uma perda articulada ao referencial paterno. O tratamento analítico dessa mulher permite a Freud reportar o sintoma de repulsa alimentar a conflitos infantis que incidiam no lugar representado pela comida na relação com o imperativo materno. $\mathrm{O}$ trajeto associativo desemboca na seguinte lembrança: a mãe, muito severa, forçava-lhe a comer toda a comida que estivesse no prato. $\mathrm{O}$ resto de carne muitas vezes permanecia como estava por duas horas após terminada a refeição, devendo ser ingerida fria, dura e gordurosa. Outra lembrança aflitiva remontava à obrigação imposta pela mãe de agir naturalmente à mesa quando estava acompanhada dos irmãos tuberculosos, para que ninguém soubesse de tal enfermidade. As dificuldades de separação da figura materna residem na matriz dos impasses psíquicos dessa moça. A recusa à comida inscreve-se, para Freud, enquanto um sintoma da impossibilidade de dizer não e imprimir uma distância frente ao Outro materno. Emmy Von N. executa, em vez disso, uma manobra a fim de fazer valer seu desejo por vias mais incapacitantes.

Assim como não há texto freudiano dedicado especificamente à anorexia, Lacan também não deixou nenhum escrito ou conferência que explore mais minuciosamente este e outros distúrbios alimentares. Contudo, algumas de suas observações pontuais podem nos servir de bússola neste terreno. $\mathrm{Na}$ segunda metade dos anos 1950, período consagrado como o primeiro ensino lacaniano, suas formulações também seguem o fio condutor da assimilação da anorexia à estrutura histérica. A anorexia é concebida como uma atualização no corpo da insatisfação desejante. Dito de outro modo, seria a encarnação absolutamente radical da irredutibilidade da estrutura do desejo ao registro da necessidade. O desejo, como resíduo da inevitável transcrição das necessidades no domínio da linguagem, põe em evidência um real irredutível à captura pelo simbólico. Nas palavras de Lacan (1955-1956/2008), "na medida em que o homem é apanhado na dialética significante, há alguma coisa que não funciona" (p. 208). A anorexia evidenciaria uma resposta inconsciente face a um curto-circuito insustentável experimentado na subjetivação da falta desejante no laço com o Outro.

Em "A direção do tratamento e os princípios de seu poder", Lacan (1958/1998) indica que, no contexto da anorexia, o Outro materno é aquele que dá à criança "a papinha sufocante daquilo que ele tem, ou seja, confunde seus cuidados com o dom de seu amor" (p. 634). Mediante a demanda de amor que transcende qualquer apropriação imediatista do objeto, esse Outro não responderia a partir da dimensão do dom, a qual relançaria a transmissão simbólica da castração. Ou seja, aquilo que não se dá porque, em última 


\section{ARTIGOS}

instância, não se é possível ter. A defasagem na disponibilidade de objetos que promovem a saciedade circunscreve preliminarmente que para o Outro falta algo. Diferentemente disso, a oferta desmedida de objetos, regida apenas pelo registro das necessidades, apresenta-se como a-dialetizável e insuportável. A escolha intransigente pela recusa alimentar afastaria e desalienaria - ainda que de uma maneira muito ruim - o sujeito da concretude nutritiva relativa ao alimento oferecido pelo Outro. O sujeito anoréxico visaria, ainda que de uma maneira frouxa simbolicamente, extrair-se dessa confusão entre demanda e necessidade para obter um signo de amor que inscreva a falta do Outro. Nas palavras de Lacan: "joga com a recusa como um desejo" (p. 634). Um jogo em que não se joga com as representações, empedrado pela pulsão de morte. Nesse apelo à retificação da posição do Outro por meio do não comer, a tentativa de restituir a mãe desejante gera, paradoxalmente, o risco da morte orgânica, já que o sujeito acaba por negligenciar a afetação do corpo pelas necessidades de sobrevivência. Ainda que, seguindo este raciocínio, algo da estrutura do desejo pareça se fazer valer, é nítido que o princípio do prazer como regulador do psiquismo não prevalece. O sujeito não conta com a metaforização do capricho materno que é propiciada pela operação paterna. Lacan (1956-1957/1995a) também assinala que "a anorexia mental não é um não comer, mas um comer nada" (p. 85). O comer nada anoréxico não seria uma negação da atividade, mas, antes, uma rebelião brutal contra a desaparição do desejo através da instauração selvagem do nada no real. A anoréxica se alimentaria do nada, restituindo a função simbólica do objeto em sua relação com o Outro, enquanto metonímia do desejo. Essa seria a estratégia para resgatar a insatisfação desejante que move a pulsão, na medida em que nenhum objeto é capaz de preenchê-la.

Em suma, a fabricação da falta onde só havia onipotência, o rechaço da demanda do Outro pela recusa ao comer, assim como o recurso ao "desejo de nada" como índice da falta-a-ser, explicam a estratégia anoréxica neste paradigma. $\mathrm{O}$ ato de comer nada é alçado ao estatuto de metáfora que ancora a posição do sujeito frente ao desejo do Outro - um desejo que acena claudicante, mal encarnado pelo Outro primordial. Miller chega a avaliar que a anorexia poderia ser elevada à condição de "estrutura de todo desejo", tendo em vista que "o desejo, por estrutura, é desejo de nada, é desejo insatisfeito" (Miller \& Laurent, 1996-1997/2005, p. 382-383). O corpo magro encarnaria o corpo que não se satisfaz com o objeto da necessidade para manter-se vivo para o Outro enquanto objeto causa do desejo. A magreza teria o verniz do falo, sendo falicizada como objeto do desejo do Outro (Cosenza, 2014). Nesse 
tipo de caso, quando pertencente ao âmbito das neuroses, o amor edípico, a operatividade fálica do ideal do corpo magro e o recalque do erotismo oral seriam coordenadas localizáveis no circuito libidinal do sujeito.

Nesse ponto, é importante evocar que a estrutura original do sintoma histérico é o paradigma da concepção freudiana clássica do sintoma neurótico, o qual é definido como uma formação que substitui uma satisfação pulsional recalcada (Freud, 1926/1996f). Nele, as fixações autoeróticas comparecem sintomaticamente de modo disfarçado e residual, organizadas pela fantasia (Freud, 1917/1996c). O sintoma histérico mascara o desejo inconsciente e a falta de um objeto último para este. É uma formação de compromisso que representa o confronto entre as exigências pulsionais, em um empuxo infindável de saturar a ausência estrutural de uma satisfação máxima, e as exigências de renúncia, responsabilização e adiamento impelidas pela realidade. Arrima-se na função fálica e no mecanismo do recalque como limite ao excesso pulsional, embora evidencie certos entraves na inscrição sexual da pulsão. Seus mecanismos traduzem o fato de que os efeitos da apropriação da função nomeante do significante Nome-do-Pai, como via de acesso ao gozo demarcado falicamente, são acompanhados de embaraços específicos na histeria. A metáfora paterna intervém sobre os significantes do saber do Outro, conotando-os de significação fálica, o que permite ao sujeito sua articulação no caminho do desejo (Souza, 1985). Esse passo requer a inscrição de que o Outro é barrado e marcado pela castração (Lacan, 1957-1958/1995b). A histérica não quer assumir seu lugar de sujeito e arcar com o desejo e as vicissitudes que lhe são próprias. Através da fuga metonímica, se debate e resiste em estabelecer por metaforização um objeto à altura de seu desejo. Nada lhe serve. Uma satisfação mortífera se embrenha na insatisfação forjada para que o desejo não seja absorvido por nenhum objeto. Nenhum semblante parece propiciar uma parada momentânea pelo contorno do objeto causa do desejo, exprimindo, assim, sua não aceitação do limite que a castração impõe ao desejo de só poder se realizar por um possível gozo fálico que requeira o semblante como objeto (Souza, 1985). A histérica deseja ter o falo, ela se coloca no lugar do próprio falo, isto é, daquilo que pode satisfazer o outro (Lacan, 1957-1958/1995b). Ser o complemento fálico do Outro é a base de suas fantasias de sedução. Os sintomas conversivos são enigmas decifráveis que exprimem tais conflitos subjetivos em torno da renúncia de gozo convocada pelo encontro com a falta do Outro.

Estaria o quadro anoréxico inscrito por inteiro nesse domínio? Seria a recusa anoréxica expressão distorcida de uma insatisfação, a serviço da 


\section{ARTIGOS}

manutenção do desejo? Seria inteiramente equiparável à tussis nervosa de Dora, por exemplo? Cabe ressaltar algumas ponderações frente a essa possível perspectiva. Ainda que Miller afirme que a anorexia se encontra em consonância com o funcionamento do sujeito desejante, ele também advoga que, na contemporaneidade, "não estamos simplesmente ante o sintoma obsessivo bem localizado, enquadrado, que afeta o Homem dos ratos, nem ante o sintoma histérico, senão ante um uso do termo sintoma mais extenso e diversificado" (Miller \& Laurent, 1996-1997/2005, p. 379). Observa-se nessa clínica sintomas flagrantemente refratários e pouco dóceis à interpretação. Não costuma haver um questionamento enigmático sobre o sintoma, nem a abertura transferencial pela suposição de um saber inconsciente. Muito pelo contrário, como já antevia Lasègue, a relação anoréxica com o sintoma é egossintônica, de maciça identificação. O que desestabiliza e provoca desconforto é, acima de tudo, a obrigação de ceder ao apetite.

Essa equivalência entre a recusa alimentar e a demanda de amor, cujo denominador comum seria o apelo a alguma coisa mais além do objeto oferecido que remeta ao movimento desejante, parece, nesse contexto, merecedora de problematização. Juntamente à recusa da desmesura do Outro, as anoréxicas repelem manifestamente o princípio do prazer, a erotização corporal e o laço libidinal com a realidade. O imperativo ao emagrecimento culmina no apagamento acentuado dos caracteres sexuais secundários. $\mathrm{O}$ aspecto cadaverizado que assume o físico em muitos casos acaba por provocar o horror. Evidencia-se uma posição exorbitantemente alijada do gozo fálico: o corpo se desfaliciza, perde o brilho libidinal e a capacidade de operar como instrumento feminino de sedução. Evoca o triunfo da pulsão de morte, muito mais do que uma objeção a um Outro avassalador em prol da manutenção do desejo de vida.

Logo, designar a incidência da anorexia nas neuroses unicamente como sintoma do retorno de fantasias sexuais de sedução recalcadas, como recurso à insatisfação para salvaguardar a dimensão do desejo, pode não ser a orientação mais adequada para o manejo dessa clínica. Talvez manifestações dialetizáveis de recusa alimentar enquanto formação clássica do inconsciente, tais como nos exemplos freudianos de Anna O., de Emmy Von N. e mesmo da renúncia ao caviar em jogo na célebre produção onírica da Bela Açougueira, que marcava sua insatisfação histérica, precisem ser diferenciadas do modo de gozo rígido, monossintomático, incrustado nas anorexias contemporâneas.

Em um novo tempo de seu ensino, Lacan (1964/1973) concebe o inconsciente não apenas no nível da estrutura da linguagem, mas também como pulsátil, homogêneo a uma zona erógena. Essa continuidade entre o 
inconsciente simbólico e o funcionamento pulsional repercute em seus enunciados sobre a anorexia. Lacan designa o nada como objeto $a$ produzido no nível oral do desmame no tempo da separação. Ele afirma: "na anorexia mental, o que a criança come é o nada" (Lacan, 1964/1973, p. 101; grifo e tradução nossos). A ênfase migra do comer nada como metonímia do desejo, para uma tomada de posição caracterizada pela escolha de não querer ceder o objeto de gozo no laço com o Outro. $\mathrm{Na}$ anorexia, o artifício consistiria em reter o objeto nada na boca vazia, positivando-o em ato, como gozo real. Não se separando totalmente e deixando o objeto enquistado na boca, o sujeito se fixa em um funcionamento em que o gozo primário é "detido" no corpo. Lacan (1962-1963/1982) acentua que o desmame é uma operação ativa, algo "que a criança coloca em ato e não alguma coisa que ela sofre" (p. 379). E frisa que, para tanto, é preciso que se instale um "desejo de desmame". Trata-se, portanto, de uma decisão do sujeito que implica o consentimento à perda do objeto oral, ou seja, de um reviramento no laço com o Outro simbólico veiculador da função estruturante da castração.

Outro ponto também emerge nessa época da formalização lacaniana, lançando nova luz sobre a problemática da referência ao Outro em questão. Lacan (1964/1973) localiza a posição fantasmática em anorexias pela via do fantasma de desaparição. O indivíduo anoréxico responde ao encontro com o enigma do desejo do Outro pelo seu desaparecimento, em uma espécie de variante mórbida do Che Vuoi? O que ele quer de mim? transmutado na pergunta Quer ele me perder? (Lacan, 1964/1973, p. 240). Daí se depreende um enérgico componente sádico-masoquista, uma vez que da confrontação com a falta no Outro eclode uma construção desvitalizante e destrutiva. Da pergunta surge a certeza do não desejo e o corpo definha rumo ao desaparecimento. O caminho eleito é o do horror da exibição de um corpo cadaverizado e o da aparente hostilidade frente a pedidos e solicitações familiares ou médicas reabilitadoras do princípio do prazer e da manutenção do organismo. Nota-se a afiada insistência em produzir uma angústia vertiginosa no Outro. Os apontamentos do primeiro ensino de Lacan esclareceram que o jogo significante, que poderia permitir dialetizar a falta do Outro na localização do amor materno e da relação à castração que o alavanca, encontra-se aqui obstruído. Fragilizado em sua potência amorosa, o dito materno assume para o sujeito o teor cristalizado da tirania e do imperativo de gozo. A interrogação Quer ele me perder? é correlata, nesses casos, a um considerável desconforto com o corpo que seria, por sua vez, indicador de uma radical angústia originada do dano narcísico provocado por perturbações na captação do investimento amoroso do Outro. 


\section{ARTIGOS}

Ou, ainda, correlata à localização fantasmática de um Outro claudicante no lugar atribuído à criança como ser privilegiado em seu desejo. Haveria, assim, uma inconsistência arrebatadora na tomada de si como objeto amado pela instância parental. De modo bastante particularizado, pois, uma coisa é invocar o fantasma de morte por si mesmo na relação de amor com os pais, outra bem diferente é atuá-lo diretamente no real, como ocorre nessas circunstâncias. O fantasma é, sobretudo, agido, e não tanto encenado inconscientemente.

\section{Um passo a mais: sobre uma relação específica com o grande Outro}

Como pudemos mapear até agora, as considerações de Lacan apontam para uma economia mortífera envolvendo um severo impasse no laço com o Outro. Passemos a um novo salto. No final de seu ensino, a perspectiva de Lacan ganhou um importante acréscimo não muito explorado nos trabalhos psicanalíticos sobre os transtornos alimentares. No Seminário 21, Les non dupes errent, Lacan (1973-1974/Inédito) distingue a posição anoréxica da posição neurótica inferida da histeria clássica. Nesse contexto, ele tematiza a relação do sujeito com o saber, elucidando que o desejo de saber aparece inicialmente como algo atribuído ao Outro, sendo comprovável nos infindáveis "porquês" da criança. Além disso, as questões colocadas pela criança visariam satisfazer o que ela supõe que o Outro desejaria que ela perguntasse. O desejo de saber, portanto, seria relativo à localização do desejo do Outro, pois o amor ao discurso do Outro define a captura do real pelo saber (Lacan, 1973-1974/Inédito, p. 32). Lacan observa que a resposta anoréxica constitui uma exceção a esse desenrolar da economia libidinal com o Outro. Seu protótipo seria o da criança que prefere não se reportar aos adultos com questões sobre aspectos da realidade, por não considerá-los detentores de um saber válido acerca das coisas do mundo. Estabelece-se com o saber que pode ser transmitido pelo Outro uma relação similar a que se tem com o alimento, expressa por Lacan (1973-1974/Inédito) pela frase: "muito pouco para mim" (p. 32). A anoréxica quer pouco saber. Sua preocupação se restringe a definir se vai comer ou não, bem como o pouco que poderá ser ingerido. Ela fica detida em uma prática de gozo sem limites que absorve integralmente o sujeito. Não seria tanto o forçamento da abertura da falta desejante no Outro, visto que o desejo de saber encontra-se desencorajado. Como assinala Lacan, "não é o desejo que preside o saber, é o horror" (p. 82). Não há desejo, mas sim, horror ao saber. 
Desse modo, a anorexia se coaduna a uma recusa radical do saber inconsciente organizado pela articulação significante. Prevalece um estatuto do saber enquanto real, fora do sentido. Lacan trabalha esse aspecto com o uso do conceito de lalangue, cuja definição é a fala como disjunta da estrutura de linguagem, e que consiste no exercício da lalação pelo bebê como modo de gozo (Miller, 2000). Lalangue diz respeito a uma aliança originária entre a palavra e o gozo que é anterior à incidência da função organizadora do Nome-do-Pai no campo do Outro. A anoréxica se deixa absorver por um saber dessubjetivado, um saber-gozo escorado no comportamento alimentar. A fixação ao objeto nada se interpõe como uma manobra de evitamento da castração. O enigma do saber não é orientado pelo desejo, mas pelo horror que a não relação sexual lhe provoca.

Observa-se que, por outro lado, Lacan não aproxima a especificidade desta posição de gozo à foraclusão do Nome-do-Pai das psicoses. Ele deduz, sobretudo, a presença de um mecanismo de denegação radical em relação ao saber transmitido pelo Outro acerca da castração e do desejo. O Outro é desprestigiado de forma implacável enquanto parceiro detentor de um saber transmissível sobre o desejo.

O possível argumento de que se trata de uma versão contemporânea da histeria nos convida a uma investigação mais decantada. Coelho dos Santos (2016) se aproxima dessa hipótese quando busca elucidar se há uma mentalidade predominante nas psicopatologias contemporâneas:

Esta atitude que resulta, talvez, de uma radicalização histérica, rebelde a toda forma de autoridade, pronta a revelar que o "rei está nu", pode explicar por que só há gozo na transgressão, na ultrapassagem de todos os limites ou na reivindicação de ser tratado como exceção. Muito mais do que denunciar a castração do Outro isto é, sua impotência em sustentar a ordem simbólica e sua recriação - , trata-se de desafiá-lo, de humilhá-lo e de declará-lo definitivamente morto. (p. 566)

Nesta perspectiva, trata-se de perturbação da referência ao Outro da Lei simbólica, que passa a ser insistentemente confrontado e desmentido em sua autoridade na constituição psíquica, assim como na regulação dos laços. Vem a lume uma posição que se debate de modo virulento, fortemente arredia aos constrangimentos que incidem sobre o gozo. A relação ao Outro é marcada pela depreciação. A mola propulsora dessa contestação é a radicalização do fantasma histérico, enquanto a encarnação de um desejo de um mestre definitivo, consistente e absoluto, que se autorize sem lançar mão do artifício do semblante. Coelho dos Santos trilha esse caminho. Esse acirramento da posição histérica, muito mais em sua vertente de gozo na destituição do Outro 


\section{ARTIGOS}

simbólico do que na vertente simbólica de sustentação do desejo, encontra seu embasamento na discursividade dominante no contemporâneo.

Como demonstramos, a chave de Lacan para descortinar a perturbação pulsional da qual padece a anoréxica é a tese de um tipo de funcionamento psíquico em que há uma acachapante tensão junto à figura materna. A demanda materna é experimentada como imperativa, asfixiante e aprisionadora do sujeito na posição de objeto. O sujeito tenta escapar de modo "selvagem", em um ato de natureza adicta, sem o suporte consistente da significação fálica que lhe permitiria ascender, como no caso da versão clássica da histeria, à sedução paterna como fantasma organizador. A anorexia seria índice de uma precariedade da transmissão do desejo pelo Outro. Neste caso, não se trataria propriamente do recalque do real sexual, mas de seu desmentido mais banal (Coelho dos Santos, 2016). Avancemos então no que consiste a propagação do mecanismo do desmentido banal no laço social contemporâneo e quais suas repercussões clínicas.

\section{A hipótese do desmentido banal da castração e as neuroses contemporâneas}

Freud (1923/1996d; 1927/1996g) aloja o núcleo do encontro penoso com a realidade na descoberta de que a mãe não tem o pênis. Ele progride em uma cautelosa investigação acerca dos casos de neurose que são afetados por deteriorações muito preocupantes na relação com a realidade, nos quais, "em suas formas graves, significa concretamente uma fuga da vida real" (Freud, 1924/1996e, p. 205). Posteriormente, introduz a tese da divisão do eu no processo de defesa, a qual se aplica às perversões e às psicoses, assim como às neuroses em geral (Freud, 1940/1996i). Nessa ocasião, destaca que a criança, até então submetida à poderosa insistência pulsional, encontra uma experiência na realidade que lhe transmite a proibição. A continuidade da satisfação pulsional passa a representar um perigo real intolerável. Ao eu restam duas opções. Ou reconhecer essa ameaça e renunciar à satisfação pulsional, ou rejeitar a realidade e convencer-se de que não há razão para medo, conservando a satisfação. Entretanto, a resposta a esse conflito se encaminha para a adoção simultânea de duas atitudes psíquicas independentes e mutuamente contrárias: uma anula as percepções das restrições da realidade e ignora qualquer interdição; a outra, por sua vez, inscreve as consequências ameaçadoras apontadas pela realidade, as quais retornam sintomaticamente (Freud, 1940/1996i, p. 293). Uma atitude regulada pelo mundo externo requer a inscrição psíquica da 
falta materna; a outra, mais afinada com as exigências pulsionais, mantém a mãe fálica. $\mathrm{O}$ recalque seria o antídoto contra o recrudescimento desta segunda tendência (Freud, 1940/1996i). A ausência do pênis materno é traumática porque afeta o narcisismo da criança (Freud, 1923/1996d; 1927/1996g). As neuroses dão provas de que a realidade nunca é totalmente exitosa em civilizar as pulsões. $\mathrm{O}$ recalque e as sublimações podem fracassar e o eu possui uma face fortemente permeável à posição de objeto pulsional, que só pode ser contrabalanceada pela ação efetiva da autoridade paterna.

Uma pesquisa atenta mostra que Freud reconhece a existência de um desmentido importante em neuroses mais radicais. Ele o faz através da ilustração de fragmentos clínicos (Freud, 1927/1996g) marcados pelo que denomina como uma escotomização de uma parcela da realidade que faz o real comparecer de modo angustiante:

$\mathrm{Na}$ análise de dois jovens aprendi que ambos - um quando tinha dois anos de idade, e o outro quando contava dez - não haviam conseguido tomar conhecimento da morte do querido pai, haviam-na "escotomizado", e, contudo, nenhum deles desenvolvera uma psicose. [...] Contudo, a pesquisa posterior conduziu-me a outra solução para a contradição. [...]. Fora apenas uma determinada corrente em sua vida mental que não reconhecera a morte daquele; havia outra corrente que se dava plena conta desse fato. A atitude que se ajustava ao desejo e a atitude que se ajustava à realidade existiam lado a lado. Num de meus dois casos, a divisão constituíra a base de uma neurose obsessiva moderadamente grave. Em todas as situações da vida, o paciente oscilava entre duas presunções: uma, de que o pai ainda estava vivo e atrapalhava suas atividades; outra, oposta, de que tinha o direito de se considerar como sucessor do pai. Assim, posso ater-me à expectativa de que, numa psicose, uma daquelas correntes - a que se ajustava à realidade - esteja realmente ausente. (p. 158)

Interpretamos essa passagem como a exposição de uma evidência clínica de que a função do pai de representante das interdições simbólicas ou das exigências da realidade, pode ser fundamentalmente desmentida sem desencadear uma psicose. Freud circunscreve a presença simultânea de duas crenças incompatíveis entre si: "a mulher ainda tem um pênis" e "meu pai castrou a mulher" (Freud, 1927/1996g, p. 159). O encontro com a falta do Outro requer uma subjetivação articulada à Lei simbólica para que se torne a mola propulsora do desejo. A apresentação em primeiro plano de um pai potente como figura de exceção - que é suposto deter o falo que a mãe não tem - é a condição para que essa figura de autoridade ganhe eficácia na ordem simbólica: para não perder o amor do pai ideal, o sujeito se submete à sua 


\section{ARTIGOS}

Lei e identifica-se com ele. O componente traumático da castração materna é, nesse caso, simbolizado por intermédio da referência identificatória ao ideal paterno. Na perversão, o sujeito age como se a lei não estivesse ali, desmente a falta do pênis e a Lei transmitida pelo Outro simbólico. Como se pode constatar, Freud também encontrou essa mesma estratégia defensiva nas neuroses, que é suprimida ao máximo graças ao mecanismo do recalque e da internalização da autoridade paterna.

Seguindo esse fio lógico, o desprezo pela inexistência do pênis na mãe é correlato à desqualificação da função do pai, pois o exercício de sua autoridade comparece no psiquismo primeiramente por meio da fantasia da castração do pênis. Ao ressaltar o papel do desmentido da castração materna no comportamento de um menino que insistia no ato masturbatório, a despeito das proibições que incidiam sobre ele, Freud designa essa maneira de lidar com a realidade como "audaciosa" e "indiferente" à intervenção do pai. Ele enfatiza que o avesso disso é um acirrado temor da devoração pelo Outro que "pela ajuda da regressão à fase oral, assumia a forma de um medo de ser comido pelo pai" (Freud, 1940/1996i, p. 295). O rebaixamento do prestígio paterno na hierarquia geracional, tão promovido na sociedade atual, difunde esse desmentido corriqueiro da autoridade simbólica. Temos, assim, um tecido social parasitado pelo descrédito nas interdições reguladoras que anda de mãos dadas com o incentivo incessante e hedonista ao gozo, desmentindo, assim, a impossibilidade da plenitude da satisfação pulsional.

Essa demonstração teórica, por meio de claras evidências clínicas, nos autoriza a deduzir que a hipótese reapresentada aqui (Coelho dos Santos, 2016) de um desmentido banal é rigorosamente freudiana. Na medida em que a realidade não veicula da mesma maneira essa função guardiã do recalque, instaura-se a radicalização de uma posição reivindicadora de compensações aos danos narcísicos. Acreditamos que as circunstâncias clínicas envolvendo transtornos alimentares desvendam este funcionamento arisco aos constrangimentos da realidade. A miríade de comorbidades orgânicas derivadas da restrição alimentar não aciona o freio ao empuxo anoréxico de não parar de não comer.

Em um recente estudo (Oliveira \& Coelho dos Santos, 2017), ressaltamos que o estado melancoliforme atravessa em graus distintos uma grande diversidade de sujeitos, cujo principal sintoma é um transtorno alimentar. Esses prolongados estados depressivos resultam de uma recusa, revolta e indignação diante da realidade da castração, sem configurar uma melancolia propriamente dita. Nossa revisão da metapsicologia da melancolia nos permitiu colher certos aspectos do funcionamento psíquico do melancólico 
que esclarecem o lugar do Outro nas neuroses contemporâneas. A posição melancólica aponta para uma posição de revolta e indignação. Os melancólicos sentem-se ofendidos, alvos de injúria, "como se lhes tivesse sido feita uma grande injustiça” (Freud, 1917/1996c, p. 180). É possível localizar aí o estatuto de um fantasma muito característico das neuroses contemporâneas: a do consumidor insatisfeito, que cobra do Outro o gozo que lhe é devido. A posição melancoliforme do eu diz respeito ao congelamento das relações primitivas entre o sujeito e o Outro. O psiquismo é "dominado pela avidez, absorvido pela oralidade pulsional, no qual reina um modo de relação canibalesco" (Oliveira \& Coelho dos Santos, 2017, p. 253). O Outro não se constitui marcado pela falta, condição do advento do desejo.

Propomos que os transtornos do circuito da pulsão oral que definem as psicopatologias alimentares derivam do desmentido da castração do Outro materno. $\mathrm{O}$ fantasma da onipotência da mãe fálica, tão flagrante nas anorexias, impera sobre as regulações da pulsão por meio da instalação da castração como vetor da Lei do desejo. Do ponto de vista metapsicológico, o fracasso da simbolização de uma perda por meio do luto não permite que se estabeleça uma distância entre o eu e um objeto que não lhe pertence, e pode deflagrar um sentimento descomunal de vazio, bem como angústia e sentimentos de desamparo e carência ilimitados. $\mathrm{O}$ eu, incapaz de interpretar a falta como causa do desejo, se exaure em um estado melancoliforme de apego voraz e desmedido ao objeto. Quanto a esse aspecto, a depressão nas neuroses se aproxima da neurose narcísica melancólica.

Enquanto as neuroses clássicas se retroalimentam sobremaneira de conflitos psíquicos edipianos, as neuroses contemporâneas possuem em seu âmago o desmentido banal e rebelde da castração. O complexo de Édipo fornece a roupagem de romance familiar à estrutura da linguagem. Cabe frisar que, se o sujeito deve efetivamente renunciar a acreditar que tudo the é possível, não é exatamente porque tem um pai, mas porque fala (Chemana, 1991). Por falar, ele não tem acesso direto ao objeto de seu desejo. Nenhum significante pode vir a dizer sobre o que ele é, ou assegurá-lo de seu ser. Sendo assim, a incerteza sobre o que o Outro da linguagem quer é fonte de angústia. A referência ao pai se apresenta como uma mediação para lidar com o Outro. Esse pacto simbólico é humanizador e engloba um compromisso de valores: ser moral, ser justo, ser um bom filho etc. Com a desqualificação sistemática do Outro simbólico, facilmente o estado de perplexidade diante da falta do Outro é reorientado para a fetichização desgovernada de objetos de consumo.

Com efeito, o denominador comum das configurações neuróticas clássicas e contemporâneas é uma resposta fantasmática à angústia em que o 


\section{ARTIGOS}

sujeito se faz objeto do Outro. Desta forma ele tenta reter alguma marca de seu ser. Neste bojo, sustentamos a afirmativa de que o desmentido da autoridade paterna maximiza a experiência da falta do Outro como algo insuportável, como puro trauma, não dando margem à elaboração sexual do desejo. Desmente-se que nunca se foi aquilo que faltava ao Outro, numa posição fantasmática que força uma sutura da dimensão da falta. $\mathrm{O}$ sujeito regride à posição de dejeto de forma radical. A anorexia pode ser lida como uma das apresentações dessa radical perturbação psíquica. Por não poder ser um objeto $a$ absoluto para o Outro, o anoréxico se vê reduzido a nada como sujeito. Reina o fantasma de um dano narcísico irremediável.

Aproximamos essas psicopatologias de uma interpretação do real impossível como insuficiência ou ingratidão caprichosa do Outro. Elas são expressão da posição de consumidor insatisfeito que reivindica uma compensação de gozo. A decadência da função paterna não corresponde à extinção do Outro, mas a alterações nos parâmetros de organização vigentes. Subsiste a crença de um Outro ilimitado, que pode tudo. A sociedade de consumo com suas promessas de felicidade, serve-se dessa ficção oferecendo-se como este Outro provedor de objetos de satisfação para "todos os gozos". A clínica prova ser urgente refletir sobre as incidências psicopatológicas das ideologias de "libertação do poder arbitrário da autoridade", de "substituição da ordem espontânea da tradição e do extremo igualitarismo", na medida em que disseminam nos vínculos intrafamiliares a promessa de uma satisfação absoluta. Em muitos casos, a família é transmissora dessa nova ordem simbólica. Cabe-nos atentar para a intensificação da deriva pulsional nos quadros psicopatológicos relativos a esse laço social.

O lugar da criança, as concepções de parentalidade e de autoridade parental passaram por transmutações decisivas na sociedade contemporânea. O lastro social moderno ressignificou o ser da criança, criando o sentimento de infância como algo a ser resguardado pelo seio familiar e pela escolarização. Inaugurou um funcionamento mental arraigado no sintoma coletivo da criança como objeto libidinal dos pais e, por essa razão, merecedora de investimentos exclusivos. Freud (1914/1996b) nomeia esse fantasma como "sua majestade o bebê". Contudo, ele também acentua que esse tempo de privilégios e direitos da constituição subjetiva precisa ser sobreposto pela transmissão das prerrogativas e deveres da moral sexual civilizada. Os complexos de Édipo e de castração estruturam essa passagem. Nos dias atuais, esse endeusamento da criança foi maximizado e pervertido. A compreensão, a felicidade e o amor se tornaram imperativos morais, os novos direitos fundamentalmente adquiridos. 
As psicopatologias desencadeadas na infância e na adolescência - e desse escopo participam transtornos alimentares como a anorexia - são congruentes com a dificuldade parental de arcar com o próprio dano narcísico implicado no encontro com a castração. A prole como efeito se torna depositária do desmentido banal da impossibilidade de satisfação sem perda. Com isso, verifica-se que, em algumas circunstâncias, a anorexia anuncia a emergência do real do arranjo inconsciente parental talhado pelo desmentido.

\section{Referências}

Bidaud, É. (1998). Anorexia. Rio de Janeiro, RJ: Companhia de Freud.

Brousse, M. H. (2014). A psicose ordinária à luz da teoria lacaniana do discurso. In T. Coelho dos Santos, J. Santiago, \& A. Martello (Orgs.). Os corpos falantes e a normatividade do superssocial. (pp. 259-280). Rio de Janeiro, RJ: Companhia de Freud.

Chemana, R. (1991). A referência ao pai em psicanálise: passe e impasses. In A. B. do R. Teixeira (Org.). O sujeito, o real do corpo e o casal parental. (pp. 152-164). Salvador, BA: Ágalma.

Coelho dos Santos, T., \& Lopes, R. G. (2013). Psicanálise, ciência e discurso. Rio de Janeiro, RJ: Companhia de Freud.

Coelho dos Santos, T. (2016). O Outro que não existe: verdade verídica, verdades mentirosas e desmentidos veementes. Ágora: Estudos em Teoria Psicanalítica, 19(3), 565-604.

Cosenza, D. (2014). Le refus dans l'anorexie. Rennes, France: PUR Réseau des Universités Ouest Atlantique.

Freud, S. (1996a). Casos clínicos. In Edição Standard Brasileira das Obras Psicológicas Completas de Sigmund Freud. (Vol. 2). Rio de Janeiro, RJ: Imago. (Trabalho original publicado em 1893).

Freud, S. (1996b). Sobre o narcisismo: uma introdução. In Edição Standard Brasileira das Obras Psicológicas Completas de Sigmund Freud. (Vol. 14). Rio de Janeiro, RJ: Imago. (Trabalho original publicado em 1914).

Freud, S. (1996c). Conferência XXIII: Os caminhos da formação dos sintomas. In Edição Standard Brasileira das Obras Psicológicas Completas de Sigmund Freud. (Vol. 16). Rio de Janeiro, RJ: Imago. (Trabalho original publicado em 1917).

Freud, S. (1996d). A organização genital infantil: uma interpolação na teoria da sexualidade. In Edição Standard Brasileira das Obras Psicológicas Completas de Sigmund Freud. (Vol. 19). Rio de Janeiro, RJ: Imago. (Trabalho original publicado em 1923). 


\section{ARTIGOS}

Freud, S. (1996e). A perda da realidade na neurose e psicose. In Edição Standard Brasileira das Obras Psicológicas Completas de Sigmund Freud. (Vol. 19). Rio de Janeiro, RJ: Imago. (Trabalho original publicado em 1924).

Freud, S. (1996f). Inibições, sintomas e ansiedade. In Edição Standard Brasileira das Obras Psicológicas Completas de Sigmund Freud. (Vol. 20). Rio de Janeiro, RJ: Imago. (Trabalho original publicado em 1926).

Freud, S. (1996g). Fetichismo. In Edição Standard Brasileira das Obras Psicológicas Completas de Sigmund Freud. (Vol. 21). Rio de Janeiro, RJ: Imago. (Trabalho original publicado em 1927).

Freud, S. (1996h). Novas conferências introdutórias de psicanálise e outros trabalhos: Explicações, aplicações e orientações. In Edição Standard Brasileira das Obras Psicológicas Completas de Sigmund Freud. (Vol. 22). Rio de Janeiro, RJ: Imago. (Trabalho original publicado em 1933).

Freud, S. (1996i). A divisão do ego no processo de defesa. In Edição Standard Brasileira das Obras Psicológicas Completas de Sigmund Freud. (Vol. 23). Rio de Janeiro, RJ: Imago. (Trabalho original publicado em 1940).

Lacan, J. (1973). Le séminaire. Livre XI. Les quatre conceps fondamentaux de la psychanalyse. Paris, France: Seuil. (Trabalho original publicado em 1964).

Lacan, J. (1973-1974). Le séminaire. Livre XI. Les non-dupes errent. Inédito.

Lacan, J. (1982). Le séminaire. Livro X. L'angoisse. Paris, France: Seuil. (Trabalho original publicado em 1962-1963).

Lacan, J. (1995a). O seminário. Livro 4. A relação de objeto. Rio de Janeiro, RJ: Jorge Zahar. (Trabalho original publicado em 1956-1957).

Lacan, J. (1995b). O seminário. Livro 5. As formações do inconsciente. Rio de Janeiro, RJ: Jorge Zahar. (Trabalho original publicado em 1957-1958).

Lacan, J. (1998). A direção do tratamento e os princípios de seu poder. In Escritos. Rio de Janeiro, RJ: Jorge Zahar. (Trabalho original publicado em 1958).

Lacan, J. (2008). O seminário. Livro 3. As psicoses. Rio de Janeiro, RJ: Jorge Zahar. (Trabalho original publicado em 1955-1956).

Lasègue, C. (1998). Da anorexia histérica. Revista Latinoamericana de Psicopatologia Fundamental, 1(3), 158-171. (Trabalho original publicado em 1873).

Miller, J.-A. (2000). Os seis paradigmas do gozo. Opção Lacaniana, 26-27(1), 87--105.

Miller, J.-A. et al. (2004). La psicosis ordinária: La convención de Antibes. Buenos Aires, Argentina: Paidós.

Miller, J.-A., \& Laurent, É. (1996-1997). El otro que no existe y sus comités de ética. Buenos Aires, Argentina: Paidós, 2005.

Nazar, T. P. (2013). Você tem fome de quê?: três abordagens dos transtornos da alimentação. Rio de Janeiro, RJ: Companhia de Freud. 
Oliveira, F. L. G. de., \& Coelho dos Santos, T. (2017). Psicopatologia dos transtornos alimentares e seus estados melancólicos. Revista Latinoamericana de Psicopatologia Fundamental, 20(2), 247-262.

Rudge, A. M. \& Fuks, B. (2017). Corpo pulsional e seus desvarios: voz e corpo anoréxico. Ágora: Estudos em Teoria Psicanalítica, 20(1), 69-84.

Souza, O. (1985). O Nome do pai no tratamento da histeria. Revirão: Revista da Prática Freudiana, 1(3), 186-191.

\section{Resumos}

(Considerations on anorexia and specificities of contemporary neuroses)

We chose anorexia as a clinical field to elucidate what particularizes the contemporary neurotic way of relating to objects. Based on a theoretical-conceptual survey on anorexia in Freud and Lacan's psychoanalysis, we find that anorexia is mostly defined as an inscription in the literalness of the body, of the lack that makes desire move towards hysteria. That psychopathology of the oral drive circuit refers to a precarious defensive response to an Other who is fragile in his symbolic function that transmits castration. We revisit and discuss this interpretation in the light of the features of today's society, highlighting the incidence - in contemporary neuroses of a phantasmatic position inclined toward the logic of the unsatisfied consumer and the banal denial of symbolic authority.

Key words: Anorexia, psychoanalysis, contemporary neuroses, denial

(Considérations sur l'anorexie et les spécificités des névroses contemporaines)

Nous partons des anorexies comme champ clinique pour élucider ce qui particularise le mode névrotique contemporain du rapport aux objets. À partir d'un itinéraire théorico-conceptuel sur l'anorexie dans la psychanalyse de Freud et de Lacan, nous démontrons que la définition la plus répandue du symptôme anorexique en psychanalyse est l'inscription dans la littéralité du corps, du manque qui pousse le désir vers l'hystérie. Cette psychopathologie du circuit de la pulsion orale renvoie à une réponse défensive précaire à un Autre fragile dans sa fonction symbolique transmettant la castration. Nous avons revisité et problématisé cette lecture à la lumière des caractéristiques de la société actuelle, en soulignant l'incidence d'une position phantasmatique inclinée à la logique du consommateur insatisfait et au démenti banal de l'autorité symbolique.

Mots clés: Anorexie, psychanalyse, névroses contemporaines, démenti 


\section{ARTIGOS}

(Consideraciones sobre las anorexias y las especificidades de las neurosis contemporâneas)

Partimos de las anorexias, como campo clínico, para dilucidar lo que caracteriza el modo neurótico contemporáneo de relación con los objetos. A partir de un recorrido teórico y conceptual sobre el padecer anoréxico en el psicoanálisis de Freud y de Lacan, demostramos la acepción más difundida del sintoma anoréxico en el psicoanálisis, como la inscripción, en la literalidad del cuerpo, de la falta que mueve el deseo en dirección a la histeria. Dicha psicopatología del circuito de la pulsión oral, estaría relacionada a una respuesta defensiva precaria ante un Otro frágil en su función simbólica transmisora de castración. Revisitamos y problematizamos esa lectura a la luz de las características de la sociedad actual, destacando la incidencia, en las neurosis contemporáneas, de una posición fantasmática inclinada hacia la lógica del consumidor insatisfecho y hacia la desmentida banal de la autoridad simbólica.

Palabras clave: Anorexia, psicoanálisis, neurosis contemporáneas, desmentida

(Überlegungen zur Anorexie und zur Spezifität moderner Neurosen)

Anorexien wurden als klinisches Feld benutzt, um festzustellen, wie sich die zeitgenössische neurotische Art der Beziehung zu Objekten charakterisiert. Aufgrund einer theoretisch-begrifflichen Studie über Anorexie in der Psychoanalyse von Freud und Lacan beschreibt der vorliegende Artikel den von der Psychoanalyse am häufigsten benutzten Begriff der Magersucht als eine Inschrift in die Literalität des Körpers, als Mangel, der das Begehren in Richtung Hysterie steuert. Diese Psychopathologie des Kreislaufs des oralen Triebes steht in Bezug zu einer prekären Abwehrreaktion gegen einen Anderen, der geschwächt ist in seiner symbolischen Funktion der Übertragung der Kastration. Wir betrachten diese Problematik im Lichte der Merkmale der heutigen Gesellschaft und stellen sie in Frage, indem wir das Vorkommen einer phantasmatischen Position in der zeitgenössischen Neurose hervorheben, die sich der Logik des unbefriedigten Verbrauchers und der banalen Verweigerung symbolischer Autorität angleicht.

Schlüsselwörter: Anorexie, Psychoanalyse, zeitgenössische Neurosen, Verweigerung

Citação/Citation: Oliveira, F. L. G.; Santos, T. C. dos (2018, junho). Considerações sobre as anorexias e as especificidades das neuroses contemporâneas. Revista Latinoamericana de Psicopatologia Fundamental, 21(2), 309-330. http://dx.doi.org/10.1590/1415-4714.2018v$2 \ln 2 \mathrm{p} 309.6$

Editores do artigo/Editors: Profa. Dra. Ana Maria Rudge e Profa. Dra. Sonia Leite 
Recebido/Received: $10.3 .2018 / 3.10 .2018$ Aceito/Accepted: 20.4 .2018 / 4.20.2018

Copyright: (C) 2009 Associação Universitária de Pesquisa em Psicopatologia Fundamental/ University Association for Research in Fundamental Psychopathology. Este é um artigo de livre acesso, que permite uso irrestrito, distribuição e reprodução em qualquer meio, desde que o autor e a fonte sejam citados / This is an open-access article, which permits unrestricted use, distribution, and reproduction in any medium, provided the original authors and sources are credited.

Financiamento/Funding: $\mathrm{O}$ trabalho contou com fomento financeiro no âmbito da bolsa de doutorado no Brasil pela Coordenação de Aperfeiçoamento de Pessoal de Nível Superior-Capes, e de bolsa de doutorado para estágio no exterior pela Fundação de Amparo à Pesquisado Estado do Rio de Janeiro - Faperj / The research was funded by Coordenação de Aperfeiçoamento de Pessoal de Nível Superior- Capes and Fundação de Amparo à Pesquisado Estado do Rio de Janeiro - Faperj.

Conflito de interesses/Conflict of interest: As autores declaram que não há conflito de interesses / The authors have no conflict of interest to declare.

\section{Flavia Lana Garcia de Oliveira}

Doutorado e mestrado pelo Programa de Pós-graduação em Teoria Psicanalítica pela Universidade Federal do Rio de Janeiro -UFRJ (Rio de Janeiro, RJ, Br); Especialização em Psicologia Clínica Institucional - Modalidade Residência Hospitalar pelo Hospital Universitário Pedro Ernesto HUPE/UERJ (Rio de Janeiro, RJ, Br); Membro adjunto do Instituto Sephora de Ensino e Pesquisa de Orientação Lacaniana/ ISEPOL (Rio de Janeiro, $\mathrm{RJ}, \mathrm{Br}$ ).

flavialanago@gmail.com

\section{Tania Coelho dos Santos}

Pós-doutorado no Departamento de Psicanálise de Paris VIII (Paris, França); Professor Associado, nível IV no Programa de Pós-graduação em Teoria Psicanalítica pela Universidade Federal do Rio de Janeiro - UFRJ (Rio de Janeiro, RJ, Br); Pesquisadora do CNPQ nível 1 C (Brasília, DF, Br); Presidente do Instituto Sephora de Ensino e Pesquisa de Orientação Lacaniana/ ISEPOL (Rio de Janeiro, RJ, Br); Psicanalista Membro da École de La Cause Freudienne, da Escola Brasileira de Psicanálise e da Associação Mundial de Psicanálise; Membro da Associação Universitária de Pesquisa em Psicopatologia Fundamental (São Paulo, SP, Br).

taniacs@,openlink.com.br

This is an open-access article, which permits unrestricted use, distribution, the original authors and sources are credited. 